\section{The effects of strength of competing responses during conflict}

DONALDR. YELLN, W'ashburn University, Topeka, Kans. 66621

Sixty-four Ss were given training and test trials on a modified RT task to determine the effects of the relative and absolute strengths of competing responses on the spced of the response that occurs in a conflict situation. The results indicated that the response occurring in the conflict situation was significantly $(p<.01)$ faster than either of the competing responses in nonconflict situations, and also suggested that the speed of the response in the conflict situation increases as an exponential function of the absolute strengths of the competing responses.

Brown \& Farber (1951), as well as Miller (1959), have indicated that one of the effects of conflict is an increment in drive. If conflict does contribute to drive, then the intensity, or speed, of the response occurring in the conflict situation should be increased (Brown, 1961). The results of several investigations (Castaneda \& Worell, 1961; Finger, 1941) have supported this proposal. Brown \& Farber (1951) have also indicated that the degree of conflict varies as a function of both the relative and absolute strengths of the competing responses. That is, conflict is expected to increase when the difference between the strengths of the competing responses is reduced and/or when the strengths of both competing responses are increased. It would be expected, then, that variation of the relative and absolute strengths of the competing responses would be related to the intensity of the response that occurs in the conflict situation. This relationship, however. has received little experimental attention.

The present study was designed to vary the relative and absolute strengths of two competing responses and then to determine the effects of this variation on the speed of the response that occurred when both responses were simultaneously aroused. Conflict and nonconflict test trials on a RT task. modified by using two ready signals, two response keys. and one stimulus to respond, were used for this purpose. In order to vary the relative speed of the competing responses, the response to one of the ready signals was associated with shock during training trials. It was expected that the association with shock would increase the relative speed of this response during the test trials. In order to vary the absolute speed of the competing responses, the length of the foreperiod used during training trials was changed during the test trials. It was expected that these changes in the length of the foreperiod would decrease the absolute speed of the competing responses.

\section{APPARATUS}

A stimulus display panel, containing a 7.5-W white light, a doorbell buzzer, and a 40-W yellow light, was mounted vertically on a desk. The white light, used as one of the ready signals, was at tached to the upper left corner, the buzzer, used as the second ready signal, was mounted on the upper right corner, and the yellow light, which served as the stimulus to respond, was fixed to the lower center portion of the panel. An ac shock source was used to deliver a shock to the forearms of the Ss' preferred hands. The same intensity of shock, judged by $E$ to be uncomfortable, was used for all Ss. Silent Hunter timers were used to control the onset of the lights, buzzer, and shock.

A horizontal response keyboard contain. ing a plastic disk and two microswitches was attached to the writing surface of a student chair. The disk was attached to the edge of the keyboard that was nearest to the $S$. The microswitches were placed 6 in. apart in the upper left and upper right corners of the keyboard. and 12 in. away from the disk. Standard electric elocks were used to measure the latencies of the Ss' responses.

\section{PROCEDURE}

The Ss were seated facing the stimulus display panel and instructed to place the index fingers of their nonpreferred hands on the plastic disk when either the white light or the buzzer was presented alone, or when the white light and buzzer were presented together. When the yellow light was turned on, Ss pressed, using the index fingers of their nonpreferred hands, one of the microswitches. The left switch was pressed if only the white light was on, and the right switch was pressed if only the buzzer had sounded. The Ss were instructed that they were free to press either switch if both the white light and the buzzer had been presented.

After the instructions were given, the electrodes for the shock were attached to the forearms of the Ss' preferred hands. The shock was paired with the white light $(\mathrm{S}+)$ and not paired with the buzzer $(S-)$ for half of the Ss. These conditions were reversed for the other half of the Ss. The onset of the shock coincided with the onset of the yellow light. The shock was terminated when the Ss pressed the appropriate microswitch.

A total of 68 trials was administered to each $S$. Trials 1.32 were training trials and consisted of the presentation of a single ready signal, either $S+$ or $S-$, and, after an interval of $4 \mathrm{sec}$, the onset of the yellow light. The $S+$ and $S$ - ready signals were each presented, in a random order, on 16 of these trials. Shock was administered on the training trials whenever the S+ ready signal was presented. Trials $33-68$ involved an alternating sequence of training trials and either conflict (C) or nonconflict (NC) test trials. The $S+$ and $S$ - ready signals were each presented on 12 training trials during this sequence. The order of presentation of the four $\mathrm{C}$ and eight $\mathrm{NC}$ test trials was varied from $S$ to $S$. The $C$ test trials involved the simultaneous presentation of both ready signals, $\mathbf{S}+$ and $\mathbf{S}-$, and, after an interval of $1,2,3$, or $4 \mathrm{sec}$, the onset of the yellow light. The NC test trials involved the presentation of a single ready signal, either $\mathrm{S}+$ or $\mathrm{S}-$, and, after an interval of $1,2,3$, or $4 \mathrm{sec}$, the onset of the yellow light. Shock was not administered on any of the C or NC test trials. The microswitch that was pressed and the time required to press that switch were both recorded. These times were later converted to response speeds (one/time).

\section{SUBJECTS}

A total of 64 male introductory psychology students served as Ss. Each S received the 12 test trials that resulted from the combination of the three test conditions: $\mathrm{C}, \mathrm{NC}$ with $\mathrm{S}+$, and $\mathrm{NC}$ with $\mathrm{S}-$, with the four foreperiod lengths: $1,2,3$, and 4 sec.

\section{RESULTS AND DISCUSSION}

A Test Conditions by Length of Foreperiod by $\mathrm{Ss}$ analysis of variance (Lindquist, 1953) of the response speeds during the test trials was performed. This analysis indicated that the Test Conditions by Length of Foreperiod interaction (presented in Fig. 1) was significant $(F=5.82$, df $=6 / 378, p<.001)$. Subsequent analysis of the simple effects of this interaction indicated that the differences between the $\mathrm{NC}$ with $\mathrm{S}+$ and the NC with $\mathrm{S}-$ conditions at each of the foreperiods were not reliable. Association with shock during training trials, then, did not facilitate the performance of a response during test trials. lt is possible that the omission of shock during the test trials eliminated a relevant cue. and that the elimination of this cue counteracted the facilitating effects expected from the association with shock. The analysis of the simple effects also indicated that the response speeds for both of the NC conditions increased significantly $(p<.01)$ from the 1 - to the $2 \cdot \mathrm{sec}$ foreperiod, but that the increases from the 


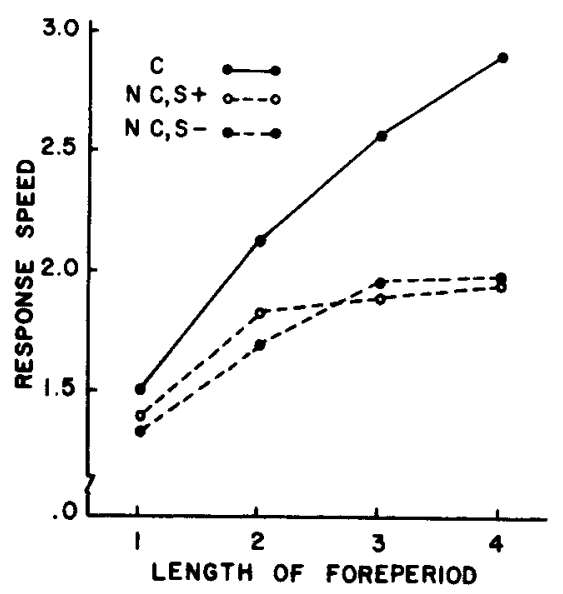

Fig. 1. Mean response speed in the C, NC with $\mathbf{S}+$, and $\mathrm{NC}$ with $\mathrm{S}-$ conditions during test trials with 1-, 2-, 3-, and 4-sec foreperiods.

2- to the 3-sec and from the 3- to the 4-sec foreperiods were not significant. These findings indicate, then, that the differences in the relative speed of the competing responses were nonsignificant during test trials with the four foreperiods, and that, as expected, the absolute speeds of the competing responses increased as a function of the length of the foreperiod.

Further analysis of the simple effects indicated that the speed of the responses in the $C$ condition were significantly $(p<.01)$ faster than the speed of the responses in both of the NC conditions during test trials with 2-, 3-, and 4-sec foreperiods, but not during test trials with a $1-\mathrm{sec}$ foreperiod; and also, that the response speeds in the $\mathrm{C}$ condition increased significantly $(p<.01)$ from the 1- to the $2-\mathrm{sec}$, from the 2 - to the $3-\mathrm{sec}$, and from the 3 - to the $4-\mathrm{sec}$ foreperiods.

Thus, the results show that the speed of the response occurring in a conflict situation is faster than the speed of either of the competing responses in nonconflict situations, and consequently, agree with previous investigations demonstrating the effects of conflict-produced drive. In addition, the results indicate, as Brown \& Farber (1951) have proposed, that the speed of the response occurring in a conflict situation is a function of the absolute strengths of the competing responses. The nature of this function is suggested by the data presented in Fig. 1. That is, Fig. 1 shows that the response speeds in the $\mathrm{C}$ condition and in both of the $\mathrm{NC}$ conditions are negatively accelerated functions of the length of the foreperiods, that the asymptote for the $\mathrm{C}$ condition is higher than the asymptote for the NC conditions, and that the slope for the $\mathrm{C}$ condition is steeper than the slope for the NC conditions. Plotting the relationship between two such negatively accelerated curves results in a positively accelerated curve, and thus suggests that the speed of the response occurring in a conflict situation increases as an exponential function of the absolute strengths of the competing responses.

\section{REFERENCES}

BROWN, J. S. The motivation of behavior. New York: McGraw-Hill, 1961

BROWN, J. S., \& FARBER, I. E. Emotions conceptualized as intervening variables-with suggestions toward a theory of frustration. Psy chological Bulletin, 1951,48, 465-495.

CASTANEDA, A., \& WORELL, L. Differential relation of latency and respons vigor to stimulus similarity in brightness diserimination. Journal of Experimental Psychology, 1961.61, 309-314.

FINGER, I. W. Quantitative studies of "conflik" I. Variations in latency and strength of the rat's response in a discrimination-jumping situation. Journal of Comparative Psy chology, 1941, 31. 97-127.

LINDQUIST, I:. I. Design and analysis of experiments in psychology and education Boston: Hough ton-Mlifflin, 1953.

MILLFR, N. F, Liberalization of basic S-R concepts: Extensions to conflict behavior, motivation and social learning. In $\mathrm{S}$. Koch ( $\mathrm{Fd}$.), Psychology: A study of a science. Vol. 2. New York: McGraw-Hill, 1959.

\section{The effects of grouping instructions in short-term memory}

JAMES M. FURUKAWA, The Johns Hopkins University, Baltimore, Md. 21218, MARY M. SUYDAM and STUART MILLER, Towson State College, Towson, Md. 21204

The effects of two levels of short-term memory (STM) and three levels of instructions were investigated in a serial. learning task. High-and low-STM Ss were assigned simple serial-learning instructions, instructions to learn by pairing words, or instructions to learn by quadrupling words. The results from this 2 by 3 , extreme-groups design showed that instructions to pair or quadnuple words significantly facilitated performance $(p<.01)$ and reduced the correlation between STM and learning from $.56(p<.05)$ to $.05 \quad(p>.05)$. The difference between high- and low-STM Ss found in an earlier study was eliminated by providing grouping instructions to the Ss.

Several early Es found that is was possible to improve memory span by either practice or specific training in study techniques, such as association formation and grouping (Gates \& Taylor, 1925; Martin \& Fernberger, 1929; Woodrow, 1927). However, these investigators did not compare the performance of Ss with different memory spans. Furthermore, the effects of grouping instructions, per se, were not determined.

Furukawa and Suydam 2 studied various determinants of the serial-position curve including short-term memory (STM). One factor which may have been responsible for the demonstrated superiority of high- over
low-STM Ss was the tendency of high-STM Ss to group adjacent items of the list into pairs. This result led to the following hypothesis: If low-STM Ss are given specific instructions to form groups of items in a serial-learning task, then their performance should more closely match that of high-STM Ss. To test the hypothesis, the materials and procedures of the Furukawa and Suydam study were used.

\section{SUBJECTS}

The Ss were 42 educational psychology students at Towson State College. Their ages ranged from 18 to 22 years, with approximately equal numbers of male and female Ss.

\section{MATERIALS}

The STM spans of the Ss were determined by the use of 20 two-digit numbers selected from a list of random numbers and 20 adjective-noun word combinations randomly selected from an history text, as shown in Table 1.

A total of $12100 \%$ association-value consonsant-vowel-consonant (CVC) trigrams were selected from Archer's norms (1960) to form a serial list. The trigrams, presented to $S s$ in alphabetical order, were: BAN, COD, DAB, FIN, GAP, HID, JON, KEG, LAD, MUG, NED, and POT.

\section{PROCEDURE}

The items used to determine STM were printed on flash-cards and presented to $S$ s in three educational psychology classes, with the following instructions:

"This is a test of your short-term memory. You will be shown a series of two-digit numbers at the rate of one 